\title{
GROUP-SPECIFIC COMPONENT (Gc) POLYMORPHISM IN JAPANESE: AN INVESTIGATION ON THE PHENOTYPIC DISTRIBUTION WITH REGARD TO THE $G c^{J}$ ALLELE
}

\author{
Mieko Kuwata, Goichi IshImoto, and Hachiro NakajlmA* \\ Department of Legal Medicine, School of Medicine, Mie University, Tsu \\ *Department of Forensic Medicine, Tokyo Medical and Dental University, Tokyo
}

\begin{abstract}
Summary Using the prolonged immunoelectrophoresis, Gc determination was performed in 1,347 plasma collected from 3 local populations in Japan. Six phenotypes determined by the codominant alleles, $G c^{1}$, $G c^{2}$ and $G c^{J}$, were observed, in which a new phenotype GcJ-J was included. This study revealed the presence of at least 3 polymorphic alleles at $\mathrm{Gc}$ locus in Japanese population.
\end{abstract}

\section{INTRODUCTION}

The group-specific component $(\mathrm{Gc})$, now established to be the binding protein for vitamin D (Daiger et al., 1975), is one of the serum proteins which show genetic polymorphism in human populations. Since Hirschfeld (1959) first discovered three common phenotypes, Gc1-1, Gc2-1 and Gc2-2, this Gc system has been utilized as a useful genetic marker for anthropological studies and in the field of forensic medicine.

In addition to the two common autosomal alleles, $G c^{1}$ and $G c^{2}$, at least 11 'rare' electrophoretic variants have been detected in various populations, most of which occur sporadically in a few families (cf. Cleve, 1973; Johnson et al., 1975). Exceptions are $\mathrm{Gc} \mathrm{Ab}$ (Aborigine) and Gc Chip (Chippewa), and they have been shown to be polymorphic (gene frequencies greater than $1 \%$ ) in some population groups of Oceania $(\mathrm{Gc} \mathrm{Ab})$ and American Indians (Gc Chip) (Cleve et al., 1963).

Recently we encountered three family cases with Gc J (Japan) variants in the course of paternity test carried out only in a year, and felt that the allele frequency for $G c^{J}$ is not extremely rare in this country (Nakajima et al., 1976; Ishimoto et al., 1976). However, there are no data on the incidence of this variant allele except for an initial report of a family with GcJ-2 (Omoto et al., 1972), although extensive population studies of $\mathrm{Gc}$ have been presented in Japanese.

Therefore, we conducted an examination of the Gc phenotypes among Japa- 
nese with careful inspection, using the method of ordinary immunoelectrophoresis that was applied in most of earlier studies. Now, we can conclude from the result of 1,347 individuals that the variant allele, $G c^{x}$, attains to be a polymorphic frequency in Japanese populations.

\section{MATERIALS AND METHODS}

In order to search the geographical variation of the phenotypic distribution within this country, the blood specimens were obtained from three different localities. They were from: 1) 337 blood donors in Fukushima Prefecture, Northeastern part of Japan. 2) 139 medical students at Tokyo Medical and Dental University and 295 healthy subjects living in Tokyo or its suburbs, which were mainly from the parents of family studies. 3) 346 medical students at Mie Universtiy and 230 blood donors in Mie Prefecture, Western Central part of Japan. To avoid any deterioration of the proteins, careful attention was paid for the storage of samples. About half of the plasma were examined within a week after bleeding in a fresh state. They were stored at $4^{\circ} \mathrm{C}$ prior to analysis. The other samples were once kept at $-20^{\circ} \mathrm{C}$ for at most one month, but never thawed before use.

Agar gel immunoelectrophoresis was performed as described by Hirschfeld (1959) with a minor modification that electrophoresis allowed to proceed until the albumin front had migrated about $7 \mathrm{~cm}$ or more. This long run enhanced a good separation of $\mathrm{Gc}$ proteins and enabled us to determine the Gc variants. The antisera to develop the precipitation line were used both polyvalent anti-human rabbit sera prepared in our laboratories and commercially available anti-Gc sera (Behringwerke and DAKO). In some instances antigen-antibody crossed electrophoresis (Laurell, 1965) and immunofixation electrophoresis (Johnson et al., 1975) were also carried out to ascertain the phenotype.

\section{RESULT AND DISCUSSION}

Six different phenotypes were calssified as shown in Fig. 1. Among them 3 common phenotypes, Gc1-1, 2-1 and 2-2, were most popular and were observed in $94.9 \%$ of 1,347 sera examined. The less common phenotypes, GcJ-1 and J-2, showed peculiar patterns as described before (Nakajima et al., 1976), and were observed in $3.5 \%$ and $1.4 \%$ of the samples, respectively. A new phenotype, proposed as GcJ-J, was also detected in 3 individuals. This type is characterized by having the fast moving variant with apparent lacking in any of the $\mathrm{Gc} 1$ or $\mathrm{Gc} 2$ component.

The two family materials with this homozygous phenotype were available, and the Gc determinations are presented in Fig. 2. As can be expected, the parents of the GcJ-J propositus had both the less common phenotypes with Ge J (Family Mat) and all children from the GcJ-J father showed the phenotype involving Gc $\mathrm{J}$ component (Family Om). Besides the pedigrees in Fig. 2, 15 families with either GcJ-1 or GcJ-2 have sofar been examined and the results are compatible with the 


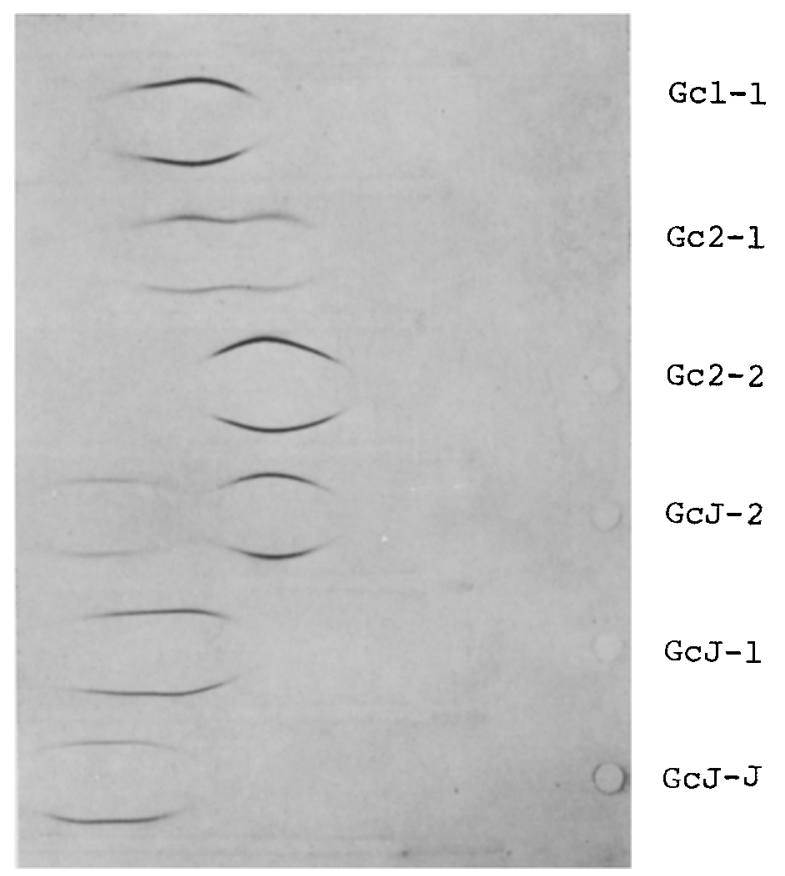

Fig. 1. Immunoelectrophoretic pattern of the six Gc phenotypes. Albumin front migrated about $8 \mathrm{~cm}$ from the origin; developed with monospecific anti-Gc (DAKO).

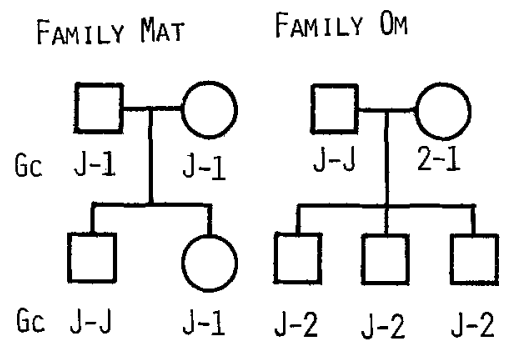

Fig. 2. Two families with the GcJ-J propositus.

assumption of the allele $G c^{\mathrm{J}}$ at the $\mathrm{Gc}$ locus.

The data of the Gc classification are specified by the localities where the samples were obtained and given in Table 1 . Gene frequencies are calculated by the gene counting method. As seen in the table, the six phenotypes described above were present in the three local populations with roughly similar frequencies. This fact suggests that the allele $G c^{J}$ is widely distributed in Japan. A slight decrease of the $G c^{J}$ towards Northern groups is recognized, but the difference is statistically not significant each other. At present it is not certain whether this trend is due to by 
Table 1. Group-specific component (Gc) phenotypes and gene frequencies in the Japanese populations.

\begin{tabular}{|c|c|c|c|c|c|c|c|c|}
\hline \multirow{2}{*}{$\begin{array}{c}\text { Local } \\
\text { population }\end{array}$} & \multicolumn{2}{|c|}{ Fukushima } & \multicolumn{2}{|c|}{ Tokyo } & \multicolumn{2}{|c|}{ Mie } & \multicolumn{2}{|r|}{ Total } \\
\hline & \multicolumn{2}{|c|}{ No. $/ \%$} & \multicolumn{2}{|c|}{ No. $1 \%$} & \multicolumn{2}{|c|}{ No..$\%$} & \multicolumn{2}{|c|}{ No. $\% \%$} \\
\hline \multicolumn{9}{|l|}{ Phenotype } \\
\hline $1-1$ & $\begin{array}{l}180 \\
53.41\end{array}$ & $\begin{array}{c}178.8 \\
53.07\end{array}$ & $\begin{array}{l}246 \\
56.68\end{array}$ & $\begin{array}{c}244.1 \\
56.24\end{array}$ & $\begin{array}{l}284 \\
49.31\end{array}$ & $\begin{array}{c}284.7 \\
49.43\end{array}$ & $\begin{array}{l}710 \\
52.71\end{array}$ & $\begin{array}{c}707.2 \\
52.50\end{array}$ \\
\hline $2-1$ & $\begin{array}{l}121 \\
35.91\end{array}$ & $\begin{array}{c}120.9 \\
35.89\end{array}$ & $\begin{array}{l}143 \\
32.95\end{array}$ & $\begin{array}{c}145.5 \\
33.53\end{array}$ & $\begin{array}{l}221 \\
38.37\end{array}$ & $\begin{array}{r}218.0 \\
37.85\end{array}$ & $\begin{array}{l}485 \\
36.01\end{array}$ & $\begin{array}{c}485.5 \\
36.04\end{array}$ \\
\hline $2-2$ & $\begin{array}{l}20 \\
5.93\end{array}$ & $\begin{array}{c}20.4 \\
6.05\end{array}$ & $\begin{array}{l}23 \\
5.30\end{array}$ & $\begin{array}{r}21.7 \\
5.00\end{array}$ & $\begin{array}{l}40 \\
6.94\end{array}$ & $\begin{array}{l}41.7 \\
7.24\end{array}$ & $\begin{array}{l}83 \\
6.16\end{array}$ & $\begin{array}{c}83.3 \\
6.18\end{array}$ \\
\hline $\mathrm{J}-1$ & $\begin{array}{l}10 \\
2.97\end{array}$ & $\begin{array}{c}12.4 \\
3.68\end{array}$ & $\begin{array}{l}16 \\
3.69\end{array}$ & $\begin{array}{c}17.3 \\
3.99\end{array}$ & $\begin{array}{l}21 \\
3.65\end{array}$ & $\begin{array}{c}22.5 \\
3.91\end{array}$ & $\begin{array}{l}47 \\
3.49\end{array}$ & $\begin{array}{c}52.1 \\
3.87\end{array}$ \\
\hline $\mathrm{J}-2$ & 5 & 4.2 & 5 & 5.1 & 9 & 8.6 & 19 & 17.9 \\
\hline & 1.48 & 1.25 & 1.15 & 1.18 & 1.56 & 1.49 & 1.41 & 1.33 \\
\hline$J_{-} \mathbf{J}$ & $\begin{array}{l}1 \\
0.30\end{array}$ & $\begin{array}{l}0.2 \\
0.06\end{array}$ & $\begin{array}{l}1 \\
0.23\end{array}$ & $\begin{array}{l}0.3 \\
0.07\end{array}$ & $\begin{array}{l}1 \\
0.17\end{array}$ & $\begin{array}{l}0.5 \\
0.09\end{array}$ & $\begin{array}{l}3 \\
0.22\end{array}$ & $\begin{array}{l}1.0 \\
0.07\end{array}$ \\
\hline Total & $\begin{array}{l}337 \\
100.0\end{array}$ & $\begin{array}{l}336.9 \\
100.0\end{array}$ & $\begin{array}{l}434 \\
100.00\end{array}$ & $\begin{array}{l}434.0 \\
100.01\end{array}$ & $\begin{array}{l}576 \\
100.00\end{array}$ & $\begin{array}{l}576.0 \\
100.01\end{array}$ & $\begin{array}{l}1,347 \\
100.00\end{array}$ & $\begin{array}{r}1,347.0 \\
99.99\end{array}$ \\
\hline $\begin{array}{l}\mathrm{Chi}^{2 *} \\
\quad(2 \mathrm{df} .)\end{array}$ & \multicolumn{2}{|c|}{$\begin{array}{l}1.062 \\
P>0.50\end{array}$} & \multicolumn{2}{|c|}{$\begin{array}{l}0.300 \\
P>0.80\end{array}$} & \multicolumn{2}{|c|}{$\begin{array}{l}0.301 \\
\quad P>0.80\end{array}$} & \multicolumn{2}{|c|}{$\begin{array}{l}1.020 \\
P>0.50\end{array}$} \\
\hline \multicolumn{9}{|l|}{ Gene } \\
\hline$G c^{1}$ & \multicolumn{2}{|c|}{0.7285} & \multicolumn{2}{|c|}{0.7500} & \multicolumn{2}{|c|}{0.7031} & \multicolumn{2}{|c|}{0.7246} \\
\hline$G c^{2}$ & \multicolumn{2}{|c|}{0.2463} & \multicolumn{2}{|c|}{0.2235} & \multicolumn{2}{|c|}{0.2691} & \multicolumn{2}{|c|}{0.2487} \\
\hline$G c^{J}$ & \multicolumn{2}{|c|}{0.0252} & \multicolumn{2}{|c|}{0.0265} & \multicolumn{2}{|c|}{0.0278} & \multicolumn{2}{|c|}{0.0267} \\
\hline
\end{tabular}

*Expected numbers below 4 were combined for chi ${ }^{2}$ calculations.

chance or indicates a regional variation for the allele. A good agreement between observed and expected numbers of the phenotypes under Hardy-Weinberg equilibrium is obtained for each population group as well as the total sample. The gene frequency for the $G c^{J}$ from the combined data is calculated as $0.0267 \pm 0.0031$.

According to the compiled data by Omoto (1975), a large number of population studies (including more than 8,300 individuals) have hitherto been carried out to examine the Gc types in Japanese, which failed to detect any variants. Now we can assume that GcJ-1 and sometimes GcJ-J have been mistyped for Gc1-1 and also GcJ-2 for Gc2-1 in the previous studies. An example of the relatively short run is shown in Fig. 3. In this case the albumin front migrated about $6 \mathrm{~cm}$ from the origin, which would be still longer than that of routine typings. This plate reveals that the distinction of GcJ-1 from Gcl-1 is still not easy, while that of $\mathrm{GcJ}-\mathrm{J}$ from $\mathrm{Gcl}-1$ is no problem.

In addition, as far as our experience is concerned, the Gc J component seemed to be much more affected by repeated freezing and thawing than other Gc components. Such a case is seen in the figure (GcJ-2 in Fig. 3). Therefore, it will 


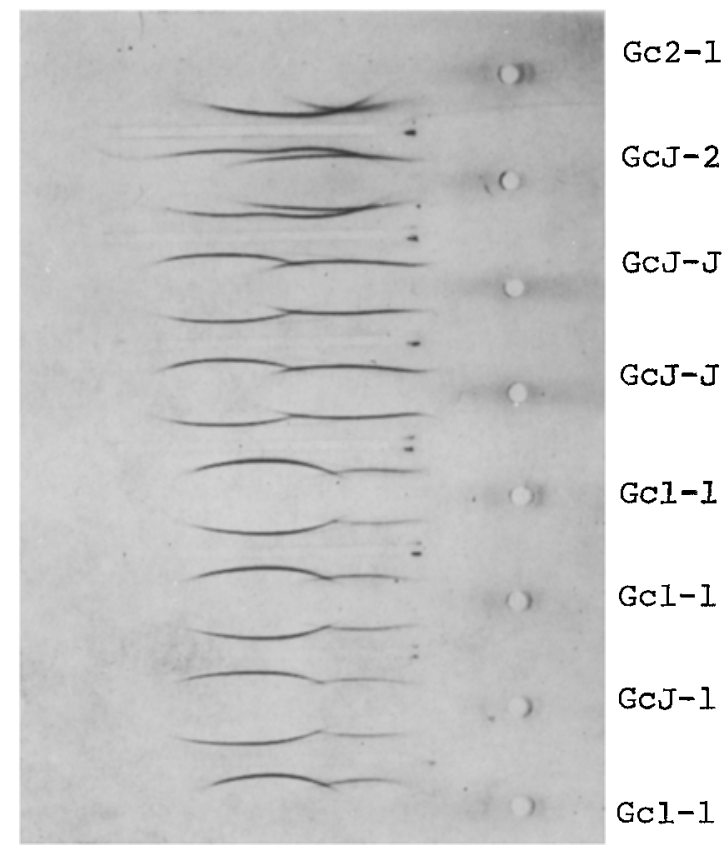

Fig. 3. Comparison of the variant and common phenotypes under a relatively 'short' run. Albumin front migrated about $6 \mathrm{~cm}$ from the origin; developed with anti-Gc (Behringwerke).

be desirable that plasma samples in a good condition are used for the Gc determination.

In this study the prolonged immunoelectrophoresis was applied throughout the samples. Other methods such as crossed immunoelectrophoresis and immunofixation electrophoresis were used only in doubtful specimens to clarify the exact Gc types. Therefore, careful attention was paid for the storage of samples and the procedure, but the possibility that the present value for the $G c^{J}(0.0267)$ is an underestimate might not be excluded, because there would be a chance of overlooking some GcJ-1.

Indeed, immunoelectrophoresis is generally not so sensitive to resolve subtle differences in electrophoretic mobility. As our criteria for the variant were only dependent on the visible mobility difference on agar plates, another possibility that a complex of fast moving variants is treated as a variant would not be excluded either. However, the present study is still worthy of demonstrating that there is more polymorphic variation at the Gc locus than sofar regarded in Japanese population.

During the preparation of this manuscript, we were aware of a paper of Daiger and Cavalli-Sforza (1977). Using autoradiography on polyacylamide gel, they 
demonstrated an anodal Gc variant with a polymorphic frequency in several ethnic groups including Japanese. The gene frequency of the variant for Japanese $(0.033)$ is slightly higher than that of $G c^{J}$ in this study, although their examined numbers are small $(\mathrm{N}=61)$. It will be possible to perform accurate $\mathrm{Gc}$ typings, if more suitable method is available for population surveys.

Recently, Constans and Viau (1977) developed a new method based on isofocusing electrophoresis to study Gc polymorphism, and succeeded in subtyping the Ge 1 components. In fact this method possesses a great resolving power, and when applied to the $\mathrm{Gc}$, it appears to work not only for detecting the variant phenotypes but also for disclosing a heterogeneity among the Gc J. Such a study is now in progress and will be reported later.

Thanks are due to Prof. N. Kuroda, Department of Legal Medicine, Fukushima Medical College, and Mr. K. Satoh, Fukushima Red Cross Blood Center, for the specimens from Fukushima blood samples. A part of this study was reported in the 61st conference of the Medico-Legal Society of Japan in May, 1977.

\section{REFERENCES}

Cleve, H. 1973. The variants of the group-specific component. Isr. J. Med. Sci. 9: 1133-1146.

Cleve, H., Kirk, R. L., Parlcer, W. C., Bearn, A. G., Schacht, L. E., Kleinman, H., and Horsfall, W. R. 1963. Two genetic variants of the group-specific component of human serum: Gc Chippewa and Gc Aborigine. Am. J. Hum. Genet. 15: 368-379.

Constans, J. and Viau, M. 1977. Group-specific component: Evidence for two subtypes of the Gc gene. Science, 198: 1070-1071.

Daiger, S. P. and Cavalli-Sforza, L. L. 1977. Detection of genetic variation with radioactive ligands. II. Genetic variants of vitamin D-labeled group-specific component $(\mathrm{Gc})$ proteins. $A m . J$. Hum. Genet. 29 : 593-604.

Daiger, S. P., Schanfield, M. S., and Cavalli-Sforza, L. L. 1975. Human group-specific component (Gc) proteins bind vitamin D and 25-hydroxy vitamin D. Prp. Natl. Acad. Sci. 72: 2076-2080.

Hirschfeld, J. 1959. Immunoelectrophoretic demonstration of qualitative differences in human sera and their relation to the haptoglobins. Acta Path. Microbiol. Scand. 47: 160-168.

Ishimoto, G., Kuwata, M., and Nakajima, H. 1976. Further examples of Gc J variants found in paternity cases. Jap. J. Legal Med. 30: 407-410 (in Japanese with English summary).

Johnson, A. M., Cleve, H., and Alper, C. 1975. Variants of the group-specific component system as demonstrated by immunofixation electrophoresis. Report of a new variant, Ge Boston (Gc B). Am. J. Hum. Genet. 27: 728-736.

Laurell, C. B. 1965 . Antigen-antibody crossed electrophoresis. Anal. Biochem. 10: 358-361.

Nakajima, H., Ishimoto, G., and Kuwata, M. 1976. Further examples of Gc variant (Gc J) found in a Japanese family. Jap. J. Human Genet. 21: 29-33.

Omoto, K. 1975. Distribution of polymorphic traits in the Japanese and neighbouring populations. 4. Serum protein groups. JIBP Synthesis, Vol. 2: 141-162.

Omoto, K., Cleve, H., and Misawa, S. 1972. A new variant phenotype of the group-specific component (Gc) found in a Japanese family. Jap. J. Human Genet. 17: 1-9. 